\title{
Analysis of the Effectiveness and Cost Benefit of Leukotriene Modifiers in Adults With Asthma in the Ohio Medicaid Population
}

\author{
PAMELA C. HEATON, PhD, RPh; JEFF J. GUO, PhD; RICHARD W. HORNUNG, DrPH; JOSEPH A. JOHNSTON, MD, MSc; \\ RAYMOND JANG, PhD; CHARLES J. MOOMAW, PhD; and ROBERT J. CLUXTON JR., PharmD
}

\begin{abstract}
OBJECTIVE: The objectives of this research were to (1) determine the association of the use of leukotriene modifiers (LMs) with 3 clinical outcome measures that can serve as proxy measures of effectiveness: subsequent emergency room visits, hospitalizations, and steroid bursts, and (2) estimate whether LM use compared with nonuse is cost beneficial from a Medicaid payer perspective.

METHODS: This was a retrospective, longitudinal study of asthma patients in the fee-for-service Ohio Medicaid program. The study population included 5,541 adult patients who were identified as having a claim containing an International Classification of Diseases, Ninth Revision, Clinical Modification (ICD-9-CM) code for asthma (code 493.xx, excluding 493.2x) in 2001. Logistic regression, controlling for selection bias through the use of propensity scores, was used to determine the association of LM use on 3 outcome measures: emergency room visits, hospitalizations, and steroid bursts. An oral steroid burst was defined as a pharmacy claim for oral prednisone in the date range from 1 day before to 3 days after an office visit that has an ICD-9-CM code for asthma. A cost-benefit analysis was also performed.
\end{abstract}

RESULTS: During the prestudy period, the LM users had higher total medical costs of $\$ 72.06$ per patient per month (PPPM, $\$ 170.60$ vs. $\$ 98.54, P<0.001$ ). During the outcome period, there was no significant association between LM use and emergency room visits (odds ratio [OR] 1.09; 95\% confidence interval $[\mathrm{Cl}]$, 0.84-1.38), hospitalizations (OR $1.02 ; 95 \% \mathrm{Cl}, 0.66-1.59$ ), or steroid bursts (OR $1.30 ; 95 \% \mathrm{Cl}, 0.89-1.90)$. Because LM use was not more effective than nonuse and is more expensive than nonuse, a situation of dominance prevails. The mean cost difference in the 3 primary outcome measures between LM users and nonusers was $\$ 1.63$ PPPM (\$34.93 vs. $\$ 33.30, P=0.019$ ).

CONCLUSION: In this study of adult Medicaid asthma patients, users of LMs did not have greater asthma control as measured by emergency room visits, hospitalizations, or steroid bursts. In this cohort of adult asthma patients with at least 1 asthma medication, there does not appear to be any cost offsets to the Ohio Medicaid program associated with the use of LMs. The use of LMs was associated with higher total costs for asthma care.

KEYWORDS: Leukotriene modifiers, Asthma, Medicaid, Cost-benefit analysis, Effectiveness

J Manag Care Pharm. 2006;12(1):33-42

Note: An editorial on the subject of this article appears on pages 80-82 of this issue.
A sthma is the most common chronic disorder in industrialized nations. In 2002, about 12 million people in the United States experienced an asthma attack or episode. During this same period, asthma was also responsible for about 13.9 million visits to private physician offices or hospital outpatient departments, 1.9 million emergency room visits, 500,000 hospitalizations, and 4,300 deaths. ${ }^{1}$ Asthma caused an economic burden on the health care system of approximately $\$ 12.7$ billion: $\$ 7.4$ billion in direct costs and $\$ 5.3$ billion in indirect costs. ${ }^{2}$

In the United States, the National Asthma Education and Prevention Program Expert Panel, working as a recommending body to the National Heart, Lung, and Blood Institute (NHLBI), defined the guidelines for the diagnosis and management of asthma in Reports I and II.-5 The pharmacological management of asthma is based upon stepwise treatment according to the level of asthma severity. The goal of therapy is to maintain a patient on a controller medication, requiring low amounts of rescue medication.

The treatment guidelines for both adults and children were updated in May 2002, and the role of leukotriene modifiers (LMs) was further substantiated. ${ }^{6}$ In patients with mild persistent asthma, inhaled corticosteroids are the preferred treatment, and LMs are listed as an alternative controller medication. In moderate

\section{Authors}

PAMELA C. HEATON, PhD, RPh, is an assistant professor of pharmacy practice; JEFF J. GUO, PhD, is an assistant professor of pharmacoeconomics and pharmacoepidemiology; RAYMOND JANG, PhD, is a professor of social and administrative sciences; and ROBERT J. CLUXTON JR., PharmD, is a professor of pharmacy practice and family medicine, College of Pharmacy, University of Cincinnati, Cincinnati, Ohio. RICHARD W. HORNUNG, DrPH, is director of biostatistics and CHARLES J. MOOMAW, PhD, is a research associate, Institute for Health Policy and Health Services Research, University of Cincinnati Medical Center, Cincinnati, Ohio. JOSEPH A. JOHNSTON, MD, MSc, is a senior clinical research physician, U.S. Outcomes Research, Eli Lilly and Company (he was an assistant professor of internal medicine, Institute for Health Policy and Health Services Research, University of Cincinnati Medical Center, Cincinnati, Ohio, at the time of this study).

AUTHOR CORRESPONDENCE: Pamela C. Heaton, PhD, RPh, Assistant Professor, College of Pharmacy, University of Cincinnati, 3223 Eden Ave., Cincinnati, OH 45267-0004. Tel: (513) 558-4177; Fax: (513) 558-0731; E-mail:Pam.Heaton@uc.edu

Copyright $\odot$ 2006, Academy of Managed Care Pharmacy. All rights reserved. 


\section{FIGURE 1) Flowchart for Patient Selection}

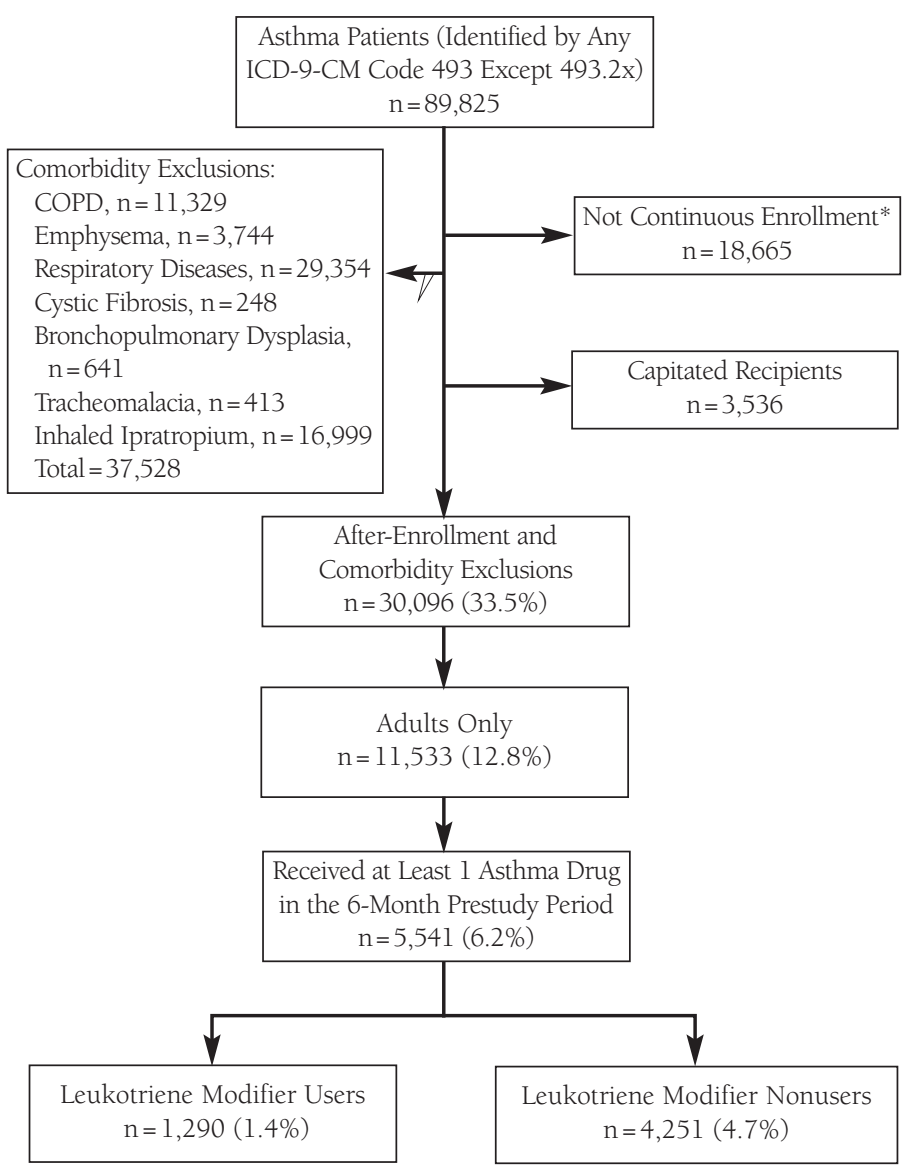

* 450 days of continuous enrollment was required, from 90 days prior to the start of the prestudy period to 90 days following the end of the outcome period. $C O P D=$ chronic obstructive pulmonary disease; ICD-9-CM = International Classification of Diseases, Ninth Revision, Clinical Modification persistent asthma, the preferred treatment is to add a long-acting beta2 ${ }^{2}$-agonist to low-to-medium doses of inhaled corticosteroids. The alternative treatment is to add an LM or theophylline to inhaled corticosteroids or to double the doses of inhaled corticosteroids.

In placebo-controlled studies, LMs appear to be efficacious. ${ }^{7-10}$ However, studies comparing LMs as monotherapy with inhaled corticosteroids have shown conflicting results. ${ }^{11,12}$ The data are also controversial regarding the effectiveness of LMs added to existing inhaled corticosteroid regimens. At least 2 studies in adults have shown that LMs provide some clinical benefit when added to an existing inhaled corticosteroid regimen. ${ }^{13,14}$ However, a study by Tonelli et al., in which LMs were added to regimens of patients who were unstable on inhaled cortico- steroids, short-acting beta 2 -agonists, or oral corticosteroids, showed no statistically significant impact on efficacy. ${ }^{15}$ Other studies show that adding LMs to inhaled corticosteroids is not as effective as adding a long-acting beta ${ }_{2}$-agonist. ${ }^{16-18}$

Several studies have examined the cost-effectiveness of LMs and again controversy exists. Some studies show that LMs are cost effective ${ }^{19}$ while others studies do not. ${ }^{20-22}$

\section{Purpose of Study}

Because the value of LMs is controversial, this study examined the effectiveness and cost benefit of LM use compared with nonuse. Effectiveness was defined as how well a patient's asthma was controlled. Three variables were selected as measures of asthma control: emergency rooms visits, hospitalizations, and steroid bursts. Thus, the purpose of this study was to determine the difference in risk-adjusted rates of emergency room visits, hospitalizations, and steroid bursts between asthmatic patients who used LMs and asthmatic patients who did not and to evaluate the cost benefit of LMs for these asthmatic patients.

\section{Methods}

\section{Study Design}

This study used a retrospective cohort design to compare the outcomes of asthma patients who used LMs with the outcomes of asthma patients who did not. Selection bias was controlled through the use of propensity scores. Drug therapies during a 180-day period and outcomes during the subsequent 90-day period were examined. The "prestudy period" is the 180-day period that was used to classify a patient's treatment group and to obtain information about variables that were used in the propensity score calculation. The subsequent 90 -day period is referred to as the "outcome period." Ninety days was chosen as the optimum length of time to measure outcomes because it was not so long a period that the outcomes would not be attributable to the drug use during the prestudy period.

\section{Data Source}

This study utilized prescription, medical service, and institutional claims from the Ohio Medicaid database obtained from the Ohio Department of Jobs and Family Services for the period from October 1, 2000, through June 30, 2002. The Ohio Medicaid fee-for-service program enrolled approximately 1.4 million recipients during this time

\section{Patient Selection}

The study included ambulatory fee-for-service recipients who had at least 1 diagnosis for asthma at any time from January 1 , 2001, to December 31, 2001, and at least 1 pharmacy claim for an asthma medication in the 6 months prior to their asthma diagnosis. An asthma diagnosis was defined as an International Classification of Diseases, Ninth Revision, Clinical Modification (ICD-9-CM) code of 493.xx, any fourth or fifth digit. Patients 
with asthma and chronic obstructive pulmonary disease (COPD) (ICD-9-CM 493.2x) were excluded. To further exclude patients with COPD or other respiratory diseases, patients were excluded if they had any prescriptions for inhaled (but not nasal) ipratropium, which does not have a role in asthma therapy, or if they had a diagnosis of emphysema (492.xx) or other respiratory diseases (495.xx-519.xx). Patients were also excluded if they had a diagnosis of cystic fibrosis (277.0), bronchopulmonary dysplasis (770.7), or tracheomalacia (748.3). (Figure 1)

Starting on January 1, 2001, for each recipient we identified the date of the first claim (day 0) that had an asthma diagnosis. The next 180 days (days 1-179) represented the prestudy period for each Medicaid recipient. The subsequent 90 days (days 180-269) represented the outcome period. Day 0 was excluded from the prestudy period calculations because it might cause overweighting for the study period since, by definition, some kind of claim was filed on the asthma identification date.

In order to calculate dose equivalents (see next paragraph), the patient must have been continuously enrolled 90 days prior to the prestudy period and 90 days following the end of the outcome period. When tallying the number of dose equivalents a patient received during a given time, issues arise with regard to date boundaries in 3 cases: (1) A prescription may have been dispensed just prior to the beginning of a patient's prestudy period. If we ignore this prescription altogether, we are not accounting for the portion of the medication that was taken during the prestudy period. (2) A prescription may have been dispensed a few days prior to the end of the prestudy period and the beginning of the outcome period. It would be misleading to assign the entire quantity dispensed to the patient's prestudy period, since some of the medicine was consumed during the prestudy period and some was consumed during the patient's outcome period. (3) A prescription may have been dispensed near the end of the outcome period; clearly, only a portion of such a prescription should be assigned to the patient's outcome period. To deal with these situations, we developed an algorithm to allocate (or prorate) pharmacy claims across date boundaries. A 90-day window before the prestudy period and after the outcome period was chosen in order to capture prescriptions that fell close to the prespecified date boundaries. Thus, in order to qualify for the study, a patient had to be continuously enrolled 90 days prior to and 360 days after the asthma diagnosis date. If the first asthma date for a recipient did not meet these qualifications but a later asthma date did, the later date was taken as day 0. Patients without 450 days of continuous enrollment $(\mathrm{n}=18,665)$ were excluded from the study.

\section{Dose Calculations}

Because many individual medications are available to asthmatics and because patients may receive different drug products within a certain drug class, comparisons were made among drug classes rather than among individual drug products. Patients may have switched products because of formulary changes, physician preferences, cost, or other reasons. Therefore, for the comparisons, quantities of short-acting beta ${ }_{2}$-agonists, long-acting beta ${ }_{2}$-agonists, inhaled corticosteroids, and LMs were converted to "dose equivalents," a common unit of measure within a drug class. This allows for summation of quantities of disparate drug products within the same drug class. For each Medicaid recipient, the sum of the dose equivalents dispensed for each medication class during the prestudy period was divided by 180 to obtain average daily doses in each class.

When attempting to equate use among the inhaled products, the question arose, "Is 1 puff of a particular inhaler equivalent to 1 puff from another product?" The World Health Organization does maintain a system of defined daily doses; however, all inhaled asthma medications have not been assigned conversation factors. Therefore, we calculated conversions for each of the inhaled products. For example, each inhaled corticosteroid pharmacy claim was converted to a beclomethasone equivalent (BME) in which 1 BME equals 1 microgram of beclomethasone. To calculate the BME, the quantity dispensed was divided by the package size, yielding the number of canisters dispensed. The number of canisters was multiplied by the number of puffs per canister. The number of puffs was multiplied by the strength to calculate the total number of micrograms dispensed. Some inhaled corticosteroids are more potent than others. Fluticasone propionate is more potent than beclomethasone dipropionate (which is equal in potency to budesonide) by a ratio of 1 to 0.5 . Beclomethasone dipropionate and budesonide, in turn, are more potent than triamcinolone acetonide (which is equal in potency to flunisolide) by a ratio of 0.5 to 0.25 . Therefore, the total number of micrograms was multiplied by the following conversion factors: 2 for fluticasone, 1 for beclomethasone and budesonide, and 0.5 for triamcinolone and flunisolide.

For short-acting beta $_{2}$-agonists, each prescription was converted to albuterol equivalents (AEs). One AE equals 1 puff of albuterol. The calculation of the number of AEs varied depending on the delivery system of the drug. For metered-dose inhalers, the quantity dispensed was divided by the package size to yield the number of canisters. The number of canisters was multiplied by the number of puffs per canister to obtain the total number of puffs. The number of puffs was then multiplied by a conversion factor of 2 for inhaled bitolterol because bitolterol is more potent. No other short-acting beta ${ }_{2}$-agonist had a conversion factor. For nebulizer solution, the quantity dispensed was multiplied by the strength. This result was then multiplied by a conversion factor to approximate the number of puffs or AEs that would be contained in the prescription. The conversion factors were as follows: 7.5 for metaproterenol, 1.25 for albuterol, 0.625 for nebulized bitolterol, and 0.16 for levalbuterol. For albuterol rotahaler, the quantity dispensed was 
multiplied by 2 to equal the number of puffs. For long-acting beta $2_{2}^{-}$ agonists, each prescription was converted to a number of salmeterol equivalents (SEs). One salmeterol equivalent equals 2 puffs (42 mcg) of salmeterol.

LMs were converted to an equivalent that represents the recommended dose for 1 day of therapy, i.e., 1 LM equivalent (LME) is equal to $10 \mathrm{mg}$ montelukast, $40 \mathrm{mg}$ zafirlukast, or 2,400 mg zileuton ( 1 tablet 4 times daily). Patients must have received at least 30 LMEs during the prestudy period, or more than 0.16 LMEs per day (30 LMEs/180days) to be classified as a leukotriene user.

\section{Outcome Variables}

Three outcomes (dependent variables) were measured: emergency room visits, hospitalizations, and steroid bursts. Asthma-related hospitalizations and emergency room visits were determined from institutional claims that contained an ICD-9-CM code for asthma. An emergency room visit that led to an immediate hospital admission was considered to be part of the hospitalization event and not an emergency room visit. Oral steroid bursts were used as an indicator of asthma exacerbations. An oral steroid burst was defined as a pharmacy claim for oral prednisone in the date range of 1 day before to 3 days after an office visit that has an ICD-9-CM code for asthma. Since prednisone has many uses, this time restriction increased the likelihood that the drug was being used for an asthma exacerbation. On the other hand, this definition likely underestimated the actual number of oral steroid bursts because it would not capture refill prednisone prescriptions or pharmacy claims for prednisone outside the date range around a medical office visit with an ICD-9-CM code for asthma.

\section{Propensity Scores}

Propensity scores, which control for the probability of a patient's receiving a particular treatment based on observed baseline characteristics, were used to control for selection bias inherent in observational database research. ${ }^{24}$ Patients with similar propensity scores have baseline characteristics that are similar enough that their probability of receiving treatment or not receiving treatment is the same. The use of propensity scores can reduce selection bias by $90 \% .25,26$ Control of selection bias is important when studying asthma because asthma severity dictates drug treatment.

The propensity score calculation included variables that controlled for demographics, certain comorbidities, and drug use other than LMs. Demographics included race, age, and gender. The ICD-9-CM codes for these diseases were obtained from institutional and medical service claims. Comorbidities that may predict poor asthma outcomes were included in the propensity score model, including obesity ${ }^{27-29}$ (ICD-9 codes 278.xx), depression ${ }^{30,31}$ (296.xx, 311.xx, 309.0, 313.1, 309.4, 300.4, 309.1, 298.0), allergies (477.xx), sinusitis ${ }^{30}$ (461.xx, 473.xx), gastroesophageal reflux disease (530.81), status asthmaticus (493.x1), and smoking (472.1, 528.6, 305.1). While there are no data to confirm the validity of all of the coding for these comorbidities, especially smoking, the comorbidities were included in the propensity model in an attempt to achieve equal treatment groups. As long as the validity of coding does not vary by whether or not the patient received LMs, these codes are useful and reliable for identifying potential treatment confounders.

Five different drug classes were covariates in the propensity score since drug use can be used as a predictor of disease severity in asthmatics. High dose short-acting beta $a_{2}$-agonists have been used as a marker of severity; however, high use may reflect lack of control, not severity. The dose of inhaled corticosteroids is a more valid marker of disease severity. ${ }^{32}$ It is, in part, because of this validity in predicting asthma severity that it was necessary to equate use among inhaled corticosteroid users by calculating dose equivalents. All drug-use variables were continuous-that is, the variables did not simply indicate whether a patient had ever received an asthma drug; instead, they indicated the number of dose equivalents or the number of pharmacy claims. Dose equivalents were calculated for short-acting beta ${ }_{2}$-agonists, inhaled corticosteroids, and inhaled long-acting beta ${ }_{2}$-agonists. Prescription counts (i.e., number of pharmacy claims regardless of quantity) were ascertained for all theophylline, cromolyn, and oral long-acting beta ${ }_{2}$-agonists (i.e., $4 \mathrm{mg}$ albuterol sulfate).

The propensity score was calculated through logistic regression, with treatment assignment as the binary response and the explanatory variables as covariates. First, a series of $t$ tests of equality of means for continuous variables and chi-square tests of independence for categorical variables were performed to compare the initial amount of bias between the LM user and the LM nonuser group for each variable. Next, multiple logistic regression was used to calculate the propensity score for each patient. Patients were then separated into quintiles defined by their propensity score to test whether balance, i.e., no remaining statistical differences between the groups, within the quintiles had been achieved..$^{33}$

\section{Statistical Analysis}

Descriptive statistics such as mean, standard deviation, median, and range were calculated for both independent and dependent variables. Logistic regression was used to examine the relationship between the outcome variables and the independent variable, LM use, as a binary variable. Because balance was not achieved in the propensity model for inhaled corticosteroids and short-acting beta ${ }_{2}$-agonists, the final model had 4 independent variables: inhaled corticosteroids, short-acting beta ${ }_{2}$-agonists, LM use, and the propensity probability.

\section{Economic Evaluation}

Cost-benefit analysis is an economic evaluation that compares the benefit, measured in dollars, of 2 alternative programs or 
interventions. Cost-benefit analysis usually compares program outcomes or interventions from a societal perspective; therefore, it requires the inclusion of indirect costs. The Medicaid claims database, however, contains provider payment amounts for many direct medical services received by patients, but it does not contain indirect costs. Since the perspective of this study is from that of the third-party payer, Medicaid, we performed a cost-benefit analysis using only direct medical costs.

The program costs were calculated as the difference in mean total asthma costs during the study period between the patients who received LMs and the patients who did not. All asthma drug costs, not only LM costs, were included because of the substitutive nature of drug treatment. Since if one drug is used, another drug may not be used, this offset in utilization needs to be taken into account. We also took nondrug asthma-related utilization, e.g., physician services, laboratory fees, and miscellaneous services, into account (see Table 5). Cost was defined as the actual amount paid by Medicaid, not the amount billed by a provider. The program benefits were the difference in mean costs for expenditures during the outcome period for the 3 clinical outcome measures: emergency room visits, hospitalizations, and steroid bursts. Costs are expressed in 2001-2002 dollars. We used the Mann-Whitney $U$ test to compare the distribution of costs between the leukotriene users and nonusers.

\section{Results}

\section{Patient Selection}

After all exclusion and inclusion criteria were applied, we had a cohort of 11,533 recipients aged 18 years or older. Further evaluation of the data revealed that there were 5,992 patients (52\%) identified with an asthma diagnosis who did not receive any asthma medications during the 6-month study period. These patients were determined to be either extremely mild asthmatics or miscoded as asthmatic, so we excluded them from the study. This resulted in a final cohort of 5,541 asthma patients (Figure 1).

\section{Description of LM Use}

Of the final cohort of 5,541 patients, 1,412 (25.5\%) received LMs. However, 122 of the patients receiving LMs (8.6\%) had use below 30 equivalents during their study period, and these patients were considered LM nonusers. Of the LM users whose use was at least 30 equivalents $(n=1,290 ; 23.3 \%)$, the mean equivalent LM use during the 180-day study period was 112.24 (SD 53.88; range, 30-420), and the mean number of LM pharmacy claims was 3.82 (SD 1.93; range, 0.58-25.83).

\section{Propensity Score Calculation}

The first step to calculate the propensity score was to determine if there was imbalance, i.e., a statistical difference, among the covariates in the 2 treatment groups. The treatment groups were not balanced in 10 out of 20 variables (Table 1), indicating that there was selection bias. Propensity scores were calculated for

\begin{tabular}{|c|c|c|c|c|}
\hline Characteristic & $\begin{array}{l}\text { All Patients } \\
(\mathrm{n}=5,541)\end{array}$ & $\begin{array}{l}\text { Leukotriene } \\
\text { Modifier } \\
\text { Users } \\
(n=1,290)\end{array}$ & $\begin{array}{c}\text { Leukotriene } \\
\text { Modifiers } \\
\text { Nonusers } \\
(\mathrm{n}=4,251)\end{array}$ & $P$ Value* \\
\hline Age, mean [SD] & $40.8[14.5]$ & 41.2 [13.9] & $40.6[14.6]$ & 0.182 \\
\hline $\begin{array}{l}\text { Gender: } \\
\text { Female, \% } \\
\text { Male, \% }\end{array}$ & $\begin{array}{l}81.6 \\
18.4\end{array}$ & $\begin{array}{l}82.2 \\
17.8\end{array}$ & $\begin{array}{l}81.4 \\
18.6\end{array}$ & 0.538 \\
\hline $\begin{array}{l}\text { Race: } \\
\text { White, \% } \\
\text { Other, \% }\end{array}$ & $\begin{array}{l}68.7 \\
31.3\end{array}$ & $\begin{array}{l}73.0 \\
27.0\end{array}$ & $\begin{array}{l}67.4 \\
32.6\end{array}$ & $<0.001$ \\
\hline $\begin{array}{l}\text { Comorbidities, \%: } \\
\text { Obesity } \\
\text { Depression } \\
\text { Allergies } \\
\text { Sinusitis } \\
\text { GERD } \\
\text { Status asthmaticus } \\
\text { Smoking }\end{array}$ & $\begin{array}{r}8.6 \\
32.6 \\
18.5 \\
22.0 \\
12.1 \\
6.4 \\
11.6\end{array}$ & $\begin{array}{r}9.6 \\
33.2 \\
24.2 \\
23.6 \\
12.2 \\
8.5 \\
9.4\end{array}$ & $\begin{array}{r}8.3 \\
32.5 \\
16.8 \\
21.5 \\
12.1 \\
5.8 \\
12.2\end{array}$ & $\begin{array}{r}0.157 \\
0.635 \\
<0.001 \\
0.107 \\
0.884 \\
0.001 \\
0.005\end{array}$ \\
\hline $\begin{array}{l}\text { Drug utilization, mean }[S D] \\
\text { Short-acting }\end{array}$ & 487.1 [568.8] & $560.3[702.5]$ & $465.0[519.6]$ & $<0.001$ \\
\hline $\begin{array}{l}\text { Short-acting } \\
\text { beta,-agonist, oral } ¥\end{array}$ & $0.06[0.52]$ & $0.08[0.59]$ & $0.05[0.50]$ & 0.253 \\
\hline $\begin{array}{l}\text { Long-acting } \\
\text { beta } \text {-agonist, inhaler }^{\dagger}\end{array}$ & $40.0[88.0]$ & $64.6[107.6]$ & $32.5[79.6]$ & $<0.001$ \\
\hline $\begin{array}{l}\text { Long-acting } \\
\text { beta } 2 \text {-agonist, oral } ¥\end{array}$ & $0.09[0.66]$ & $0.17[0.92]$ & $0.07[0.56]$ & $<0.001$ \\
\hline Inhaled corticosteroids $\dagger \|$ & $\begin{array}{r}28,096.5 \\
{[53,897.5]}\end{array}$ & $\begin{array}{r}44,307.7 \\
{[68,515.2]}\end{array}$ & $\begin{array}{r}23,177.1 \\
{[47,528.2]}\end{array}$ & $<0.001$ \\
\hline Theophylline $\ddagger$ & $0.30[1.24]$ & $0.46[1.48]$ & $0.26[1.15]$ & $<0.001$ \\
\hline Cromolyn $\neq$ & $0.07[0.59]$ & $0.08[0.65]$ & $0.06[0.57]$ & 0.213 \\
\hline $\begin{array}{l}\text { Other factors, no. of patients } \\
\text { ER visitsII } \\
\text { HospitalizationsI } \\
\text { Steroid bursts I }\end{array}$ & $\begin{array}{r}844(15.2 \%) \\
264(4.8 \%) \\
320(5.8 \%)\end{array}$ & $\begin{array}{r}207(16.0 \%) \\
67(5.2 \%) \\
119(9.2 \%)\end{array}$ & $\begin{array}{r}637(15.0 \%) \\
197(4.6 \%) \\
201(4.7 \%)\end{array}$ & $\begin{array}{r}0.353 \\
0.412 \\
<0.001\end{array}$ \\
\hline \multicolumn{5}{|c|}{$\begin{array}{l}\text { * Leukotriene modifier users compared with leukotriene modifier nonusers; Student's t test } \\
\text { for continuous variables, chi-square test for all other comparisons. } \\
\dagger \text { Measured in dose equivalents. } \\
\text { ₹ Measured as number of prescriptions. } \\
\text { \& Dose equivalents per } 100 \text { units. } \\
\text { II Dose equivalents per } 10,000 \text { units. } \\
\text { II ER visits, hospitalizations, and steroid bursts that occurred during the 6-month } \\
\text { prestudy period. } \\
\text { ER=emergency room; GERD= gastroesophageal reflux disease. }\end{array}$} \\
\hline
\end{tabular}

each patient by logistic regression (Table 2). After calculating the propensity scores, $t$ tests of equality of means for continuous variables and chi-square tests of independence for categorical variables were performed for each variable within each quintile to determine whether patients were balanced within quintiles. Overall, good balance was achieved; however, short-acting beta $_{2}$-agonist use and inhaled corticosteroid use were not suffi- 


\begin{tabular}{|c|c|c|}
\hline Characteristic & Odds Ratio & $95 \% \mathrm{CI}$ \\
\hline Age, years & 1.00 & $1.00-1.01$ \\
\hline $\begin{array}{l}\text { Gender: } \\
\text { Female }\end{array}$ & 1.05 & $0.90-1.24$ \\
\hline Race, nonwhite & 0.76 & $0.66-0.88$ \\
\hline $\begin{array}{l}\text { Comorbidities: } \\
\text { Obesity } \\
\text { Depression } \\
\text { Allergies } \\
\text { Sinusitis } \\
\text { GERD } \\
\text { Status asthmaticus } \\
\text { Smoking }\end{array}$ & $\begin{array}{l}1.18 \\
1.02 \\
1.47 \\
1.01 \\
0.97 \\
1.36 \\
0.78\end{array}$ & $\begin{array}{l}0.94-1.47 \\
0.89-1.17 \\
1.25-1.72 \\
0.87-1.19 \\
0.80-1.18 \\
1.06-1.74 \\
0.63-0.97\end{array}$ \\
\hline 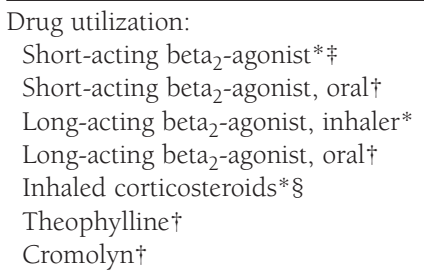 & $\begin{array}{l}1.01 \\
1.07 \\
1.00 \\
1.15 \\
1.04 \\
1.07 \\
1.01\end{array}$ & $\begin{array}{l}1.00-1.02 \\
0.95-1.19 \\
1.00-1.00 \\
1.05-1.25 \\
1.03-1.05 \\
1.02-1.12 \\
0.91-1.11\end{array}$ \\
\hline $\begin{array}{l}\text { Other factors: } \\
\text { Emergency room visit|| } \\
\text { Hospitalization\| } \\
\text { Steroid burst|| }\end{array}$ & $\begin{array}{l}1.11 \\
1.07 \\
1.67\end{array}$ & $\begin{array}{l}0.92-1.33 \\
0.79-1.45 \\
1.30-2.14\end{array}$ \\
\hline
\end{tabular}

* Measured in dose equivalents.

$\dagger$ Measured as number of prescriptions.

¥Dose equivalents per 100 units.

$\S$ Dose equivalents per 10,000 units.

II ER visits, hospitalizations, and steroid bursts that occurred during the

6-month prestudy period.

$C I=$ confidence interval; $G E R D=$ gastroesophageal reflux disease.

ciently balanced. Therefore, these covariates were added to the final outcome regression models.

\section{Logistic Regression Results}

The final logistic regression model was created for each outcome variable. (There were a total of 399 emergency room visits, 115 hospitalizations, and 135 steroid bursts. Unadjusted for severity of illness, LM users, compared with nonusers, experienced a greater percentage of steroid bursts $(3.6 \%$ vs. $2.1 \%, P=0.002)$ but not emergency room visits (7.9\% vs. $7.0 \%$, $P=0.268)$ or hospitalizations $(2.3 \%$ vs. $2.0 \%, P=0.503)$. Because of the small number of patients who had multiple occurrences of an outcome (e.g., more than 1 emergency room visit), each outcome was reduced to a binary variable.

The logistic regression results for emergency room visits, hospitalizations, and steroid bursts are given in Table 3. The use of LMs did not have a significant effect, positive or negative, on emergency room visits, hospitalizations, or steroid bursts.

\section{Cost-Benefit Analysis}

Per-patient-per-month (PPPM) provider payments during the study period and outcome period are listed in Table 4 and Table 5, respectively. Because LM use was not more effective than nonuse and LM use is more expensive than nonuse, a situation of dominance prevails in which it is not practical to calculate a cost-benefit ratio. For this reason, the net benefit was calculated.

Because most patients did not experience 1 of these 3 outcomes, the cost data are skewed. The median cost for all 3 outcomes is 0 . Therefore, mean costs are displayed in Tables 4 and 5; the Mann-Whitney $U$ test was used to compare the distributions between the 2 groups. The mean difference in the cost outcome measures was $\$ 1.63$ PPPM (\$34.93 vs. \$33.30, $P=0.019$ ). Total direct costs during the study period were $\$ 72.06$ PPPM higher in the LM user group than in the LM nonuser group ( $\$ 170.60$ vs. $\$ 98.54, P<0.001)$. Therefore, for LM users, there is an additional cost of $\$ 72.06$ PPPM with no apparent cost offset. Use of LMs imposed additional costs for Ohio Medicaid.

\section{Discussion}

In this cohort of asthmatic patients who received at least 1 asthma prescription, 23.4\% of the patients used LMs. Patients who used LMs did not have significantly different cost outcomes compared with nonusers. The net cost benefit to Medicaid favored the nonuse of LMs.

This economic evaluation had a limited perspective and did not consider any potential advantage of LMs to patients and providers, such as convenience or incidence of side effects. For example, in patients who experience difficulty manipulating an inhaler, an oral tablet may be easier to use. Compliance taking LMs may be superior compared with patients using an inhaled corticosteroid or inhaled long-acting beta ${ }_{2}$-agonist, ${ }^{34}$ but other studies do not confirm these results. ${ }^{35}$ Side effects of LMs are usually mild and may include headache, dizziness, or nausea; however, there have been reports of liver failure with zafirlukast, ${ }^{36}$ and LMs may potentially cause Churg-Strauss syndrome. ${ }^{37}$ Side effects of inhaled corticosteroids are also usually mild and may include cough, dysphonia, or oral thrush. Since asthma is a chronic disease often requiring daily medication, the development of osteoporosis is a concern; studies, however, are inconclusive..$^{38-41}$

Selection bias is always a concern in database research. It is interesting to note in the propensity score analysis that the patients using LMs had significantly higher use of all other medications except for oral short-acting beta $a_{2}$-agonists and cromolyn and had higher rates of status asthmaticus. This concurs with other cost-effectiveness research using retrospective claims analysis, which found that, at baseline, the LM users were potentially more severe asthmatics ${ }^{22,42-45}$ although 2 studies found that the LMs were potentially used less by severe asthmatics. ${ }^{46,47}$ All of these studies did attempt to control for base- 
line differences; however, there were fewer covariates used than used in the present propensity analysis. Perhaps because of the better ability for a propensity analysis to control for selection bias, our study does not support others that found an increase in emergency room visits and hospitalizations in patients using LMs. ${ }^{45,22}$ Indeed, a prospective, longitudinal study of 349 asthma patients showed that patients receiving LMs had more severe asthma, which suggests that great care must be taken to control for selection bias. ${ }^{48}$

It is interesting that a significant predictor of LM use was allergies (odds ratio [OR] 1.47; 95\% CI, 1.26-1.73). The OR associated with allergy diagnosis may have been high because LMs are used in asthma patients with allergic rhinitis. ${ }^{49}$ The value of the use of LMs in allergic rhinitis, however, is controversial. Studies have shown that LMs have a protective effect on the pulmonary function and nasal anatomy induced by natural cat exposure in asthmatic patients. ${ }^{50,51}$ However, a recent review article on the use of LMs in treating allergic rhinitis shows that LMs are sometimes more effective than placebo, no more effective than low-sedating antihistamines, and less effective than inhaled nasal corticosteroids in reducing the symptoms of allergic rhinitis. ${ }^{52}$ Montelukast sodium (Singulair) was approved by the U.S. Food and Drug Administration (FDA) on December 31, 2002, for the additional indication for the relief of symptoms of seasonal allergic rhinitis in adults and pediatric patients aged 2 years and older. ${ }^{33}$ Lakomski and Chitre found that, for the 12-month period from September 1, 2001, through August 31, 2002 , the majority of LM use in a large managed care organization was initial monotherapy, contrary to national treatment guidelines for asthma, and an estimated 25\% of use was not for asthma. ${ }^{54}$ Both this and the present study precede the date of FDA approval of montelukast for the indication of allergic rhinitis. Zafirlukast and zileuton, which were voluntarily withdrawn from the market by the manufacturer in 2003, do not have this indication for allergic rhinitis.

\section{Limitations}

Foremost among the limitations of this study was that the leukotriene users differed significantly from the leukotriene nonusers in several measures, including a higher percentage of comorbidity for allergy and status asthmaticus but a lower percentage for smoking. Leukotriene users had higher mean utilization of short-acting beta-agonists, long-acting beta -agonists $^{2}$ (both for the oral dose form and for inhalers), inhaled corticosteroids, and theophylline. This may suggest that LMs are used in more severe asthmatics as an add-on to other controller therapy but are not as widely used as solo therapy in patients with mild persistent asthma.

Second, we used oral steroid bursts as a proxy measure for an asthma exacerbation, a method we have used previously.55 Yet, drug use can be a proxy measure of disease. For example, the chronic disease score utilizes medication use to define
TABLE 3 Adjusted Odds Ratio (95\% Confidence Interval) for Outcomes Associated With Leukotriene Modifier Use in the 90-Day Outcome Measurement Period

\begin{tabular}{|c|c|c|}
\hline Outcome Variable & Odds Ratio & $95 \%$ CI \\
\hline $\begin{array}{l}\text { Any emergency room visit } \\
\text { Leukotriene modifiers: } \\
\text { Short-acting beta } 2 \text {-agonists* } \\
\text { Inhaled corticosteroids } \dagger \\
\text { Propensity score }\end{array}$ & $\begin{array}{l}1.09 \\
1.03 \\
1.00 \\
1.26\end{array}$ & $\begin{array}{l}0.84-1.38 \\
1.01-1.05 \\
0.98-1.03 \\
0.29-5.47\end{array}$ \\
\hline $\begin{array}{l}\text { Any hospitalization } \\
\text { Leukotriene modifiers: } \\
\text { Short-acting beta } 2 \text {-agonists* } \\
\text { Inhaled corticosteroids } \dagger \\
\text { Propensity score }\end{array}$ & $\begin{array}{r}1.02 \\
1.02 \\
0.94 \\
45.93\end{array}$ & $\begin{array}{l}0.66-1.59 \\
0.99-1.05 \\
0.90-0.99 \\
4.70-448.57\end{array}$ \\
\hline $\begin{array}{l}\text { Any steroid burst } \\
\text { Leukotriene modifiers: } \\
\text { Short-acting beta } 2 \text {-agonists* } \\
\text { Inhaled corticosteroids } \dagger \\
\text { Propensity score }\end{array}$ & $\begin{array}{r}1.30 \\
1.03 \\
0.97 \\
176.14\end{array}$ & $\begin{array}{c}0.89-1.90 \\
1.00-1.05 \\
0.93-1.00 \\
27.19-1,141.06\end{array}$ \\
\hline
\end{tabular}

TABLE 4 Utilization Per Patient Per Month and [SD] Costs During the 6-Month Prestudy

\begin{tabular}{|c|c|c|c|c|}
\hline Cost Category & $\begin{array}{c}\text { All Patients } \\
(\mathrm{n}=5,541)\end{array}$ & $\begin{array}{l}\text { LM Users } \\
(\mathrm{n}=1,290)\end{array}$ & $\begin{array}{c}\text { LM Nonusers } \\
(\mathrm{n}=4,251)\end{array}$ & $P$ Value* \\
\hline Pharmacy claims (\$) & $\begin{array}{l}47.57 \\
{[60.57]}\end{array}$ & $\begin{array}{l}101.17 \\
{[73.38]}\end{array}$ & $\begin{array}{c}31.31 \\
{[44.87]}\end{array}$ & $<0.001$ \\
\hline Physician visits (\$) & $\begin{array}{c}13.98 \\
{[47.12]}\end{array}$ & $\begin{array}{c}18.89 \\
{[54.21]}\end{array}$ & $\begin{array}{c}12.49 \\
{[44.64]}\end{array}$ & $<0.001$ \\
\hline Laboratory $(\$) \dagger$ & $\begin{array}{c}2.77 \\
{[5.71]}\end{array}$ & $\begin{array}{c}2.96 \\
{[6.07]}\end{array}$ & $\begin{array}{c}2.71 \\
{[5.60]}\end{array}$ & 0.273 \\
\hline Miscellaneous services $(\$) \ddagger$ & $\begin{array}{c}7.37 \\
{[112.31]}\end{array}$ & $\begin{array}{c}5.54 \\
{[54.77]}\end{array}$ & $\begin{array}{c}7.93 \\
{[124.63]}\end{array}$ & $<0.001$ \\
\hline Emergency room visits $(\$) \S$ & $\begin{array}{c}6.54 \\
{[29.64]}\end{array}$ & $\begin{array}{c}6.16 \\
{[23.90]}\end{array}$ & $\begin{array}{c}6.65 \\
{[31.17]}\end{array}$ & 0.375 \\
\hline Hospitalizations (\$)§ & $\begin{array}{c}37.09 \\
{[227.09]}\end{array}$ & $\begin{array}{c}35.94 \\
{[203.19]}\end{array}$ & $\begin{array}{c}37.44 \\
{[233.88]}\end{array}$ & 0.638 \\
\hline Steroid bursts $(\$) \S$ & $\begin{array}{c}0.05 \\
{[0.23]}\end{array}$ & $\begin{array}{c}0.08 \\
{[0.32]}\end{array}$ & $\begin{array}{c}0.04 \\
{[0.20]}\end{array}$ & $<0.001$ \\
\hline Total & $\begin{array}{c}115.32 \\
{[271.14]}\end{array}$ & $\begin{array}{c}170.60 \\
{[236.16]}\end{array}$ & $\begin{array}{c}98.54 \\
{[278.75]}\end{array}$ & $<0.001$ \\
\hline
\end{tabular}

Utilization calculated during the 6-month prestudy period in 2001:

* Mann-Whitney U test.

$\dagger$ Includes chest X-ray, 2 views; blood gases: $\mathrm{pH}, \mathrm{pO} 2$; automated hemogram; prolonged postexposure evaluation of bronchospasm; bronchospasm evaluation; spirometry.

¥Includes nursing services, home health/waivered services, supplies, transportation, other. $\S$ Emergency room visits, hospitalizations, and steroid bursts that occurred during the 6-month prestudy period. 


\begin{tabular}{|c|c|c|c|c|}
\hline Outcome Measure* & $\begin{array}{l}\text { All Patients } \\
(\mathrm{n}=5,541)\end{array}$ & $\begin{array}{l}\text { Leukotriene } \\
\text { Modifier } \\
\text { Users } \\
(n=1,290)\end{array}$ & $\begin{array}{c}\text { Leukotriene } \\
\text { Modifier } \\
\text { Nonusers } \\
(\mathrm{n}=4,251)\end{array}$ & $P$ Value $\dagger$ \\
\hline Emergency room visits (\$) & $\begin{array}{c}5.24 \\
{[32.49]}\end{array}$ & $\begin{array}{c}5.89 \\
{[34.77]}\end{array}$ & $\begin{array}{c}5.05 \\
{[31.77]}\end{array}$ & 0.470 \\
\hline Hospitalizations (\$) & $\begin{array}{c}28.39 \\
{[255.88]}\end{array}$ & $\begin{array}{c}28.98 \\
{[225.78]}\end{array}$ & $\begin{array}{c}28.21 \\
{[264.36]}\end{array}$ & 0.089 \\
\hline Steroid bursts $(\$)$ & $\begin{array}{c}0.04 \\
{[0.29]}\end{array}$ & $\begin{array}{c}0.07 \\
{[0.37]}\end{array}$ & $\begin{array}{c}0.04 \\
{[0.26]}\end{array}$ & 0.001 \\
\hline Total (\$) & $\begin{array}{c}33.68 \\
{[259.22]}\end{array}$ & $\begin{array}{c}34.93 \\
{[228.59]}\end{array}$ & $\begin{array}{c}33.30 \\
{[267.84]}\end{array}$ & 0.019 \\
\hline
\end{tabular}

* Emergency room visits, hospitalizations, and costs associated with a diagnosis for asthma (International Classification of Diseases, Ninth Revision, Clinical Modification [ICD-9-CM] code 493, excluding 493.2x). Steroid bursts were defined as a pharmacy claim for oral prednisone 1 day prior to an office visit to 3 days following an office visit, which has an ICD-9-CM code for asthma. Utilization was calculated during the 3-month outcome period.

† Mann-Whitney U test.

certain diseases. ${ }^{56}$ The key to a good drug proxy is that its therapeutic use is narrow, e.g., insulin in diabetics, thereby increasing the likelihood that the patient does, in fact, have that condition. Unfortunately, steroid bursts have many uses. To ensure that we were not overestimating the number of bursts associated with asthma disease management, we required that the burst be dispensed 1 day before to 3 days after a physician visit that had an ICD-9-CM code for asthma. However, this definition may have underestimated the occurrence of steroid bursts because pharmacy claims would not be captured for prednisone refills or new prednisone prescriptions outside this relatively narrow date range around a medical office visit with an ICD-9-CM code for asthma.

Third, this study is also limited by the factors that impact all research with administrative claims, such as upcoding for reimbursement purposes or disease misclassification. For example, $5,992(52 \%)$ of the patients who would otherwise have been included in this study had a diagnosis of asthma but did not receive asthma medication. These may be very mild asthma patients, patients who do not actually have asthma, or asthma patients who received prescription samples from their physician. However, if their only prescription was for an LM that was being used for allergic rhinitis or off-label for urticaria, and the diagnosis was misclassified as asthma, the results would be biased to the null hypothesis, i.e., that there is no difference in utilization or costs between the LM users and nonusers. We also did not calculate an estimate of the magnitude of this potential threat by determining the number and proportion of the 5,541 asthma patients who were identified by only 1 claim with an asthma diagnosis.

Fourth, we assumed that a filled prescription is consumed. We could not determine patient compliance with a medication or whether a patient correctly used a spacer for inhaled medications.

Fifth, while propensity score analysis has been shown to be a valid method to reduce selection bias, it can only control for known variables, not unknown variables. Also, the Medicaid database does not contain any clinical variables such as changes in $\mathrm{FEV}_{1}$ (forced expiratory volume in 1 second) values or changes in nocturnal awakenings. A major component of this study, however, examined drug utilization, which has been shown to be very reliable in a Medicaid database. ${ }^{57}$

Finally, this study looked at the class of LMs and not at individual drugs. The Ohio Medicaid asthma treatment guidelines do not specify one LM over another.

\section{Conclusion}

In this study of adult Medicaid asthma patients, the use of LMs was not associated with clinical effectiveness in asthma control as measured by lower use of emergency room visits, hospitalizations, or steroid bursts. In this cohort of adult asthma patients with at least 1 asthma medication, there does not appear to be any cost offsets to the Ohio Medicaid program associated with the additional direct drug costs of LMs, and PPPM costs were $4.9 \%$ ( $\$ 1.63$ ) higher for the 3 primary outcome measures for users of LMs versus nonusers.

\section{DISCLOSURES}

This project was conducted under an interagency agreement with the University of Cincinnati and the Ohio Department of Jobs and Family Services through the Ohio Medicaid Technical Assistance Policy and Program (MEDTAPP). The results and opinions expressed do not necessarily represent the official views of the Ohio Department of Jobs and Family Services. No outside funding supported this research. All authors but Joseph A. Johnston are currently employed by the University of Cincinnati; Johnston was formerly employed at the university's medical center. The authors disclose no potential bias or conflict of interest relating to this article.

Author Pamela C. Heaton served as principal author of the study. Study concept and design were contributed primarily by Heaton, with input from authors Jeff J. Guo, Richard W. Hornung, Joseph A. Johnston, Raymond Jang, and Robert J. Cluxton Jr. Data collection was the work of author Charles J. Moomaw, with input from Heaton and Hornung; data interpretation was primarily the work of Hornung, Heaton, and Moomaw, with input from the coauthors. Drafting of the manuscript and its revision were primarily the work of Heaton, with input from the coauthors.

\section{REFERENCES}

1. National Center for Health Statistics APHCUaM2. Available at: http://www.cdc.gov/nchs/products/pubs/pubd/hestats/asthma/asthma.htm. Accessed May 10, 2005.

2. Weiss KB, Sullivan SD. The health economics of asthma and rhinitis. I. Assessing the economic impact. J Allergy Clin Immunol. 2001;107:3-8

3. Podell R. National guidelines for the management of asthma in adults. Am Fam Physician. 1992:46:1189-96. 


\section{Analysis of the Effectiveness and Cost Benefit of Leukotriene Modifiers in Adults With Asthma in the Ohio Medicaid Population}

4. National Heart, Lung, and Blood Institute. Guidelines for the Diagnosis and Management of Asthma. Bethesda, MD: National Heart, Lung, and Blood Institute; 1997. NIH publication 97-4051

5. Doerschug KC, Peterson MW, Dayton CS, Kline JN. Asthma guidelines: an assessment of physician understanding and practice. Am J Respir Crit Care Med. 1999;159:1735-41

6. National Heart, Lung, and Blood Institute. Guidelines for the Diagnosis and Management of Asthma. Update on Selected Topics 2002. Bethesda, MD: National Heart, Lung, and Blood Institute; 2002. NIH publication 02-5075.

7. Fish JE, Kemp JP, Lockey RF, et al. Zafirlukast for symptomatic mild-tomoderate asthma: a 13-week multicenter study. The Zafirlukast Trialists Group. Clin Ther. 1997;19:675-90.

8. Nathan RA, Bernstein JA, Bielory L, et al. Zafirlukast improves asthma symptoms and quality of life in patients with moderate reversible airflow obstruction. J Allergy Clin Immunol. 1998;102:935-42.

9. Adkins JC, Brogden RN. Zafirlukast. A review of its pharmacology and therapeutic potential in the management of asthma. Drugs. 1998;55:121-44.

10. Suissa S, Dennis R, Ernst P, et al. Effectiveness of the leukotriene receptor antagonist zafirlukast for mild-to-moderate asthma. A randomized, doubleblind, placebo-controlled trial. Ann Intern Med. 1997;126:177-83.

11. Bleecker ER, Welch MJ, Weinstein SF, et al. Low-dose inhaled fluticasone propionate versus oral zafirlukast in the treatment of persistent asthma. J Allergy Clin Immunol. 2000;105:1123-29.

12. Bukstein DA, Henk HJ, Luskin AT. A comparison of asthma-related expenditures for patients started on montelukast versus fluticasone propionate as monotherapy. Clin Ther. 2001;23:1589-1600.

13. Laviolette M, Malmstrom K, Lu S, et al. Montelukast added to inhaled beclomethasone in treatment of asthma. Montelukast/Beclomethasone Additivity Group. Am J Respir Crit Care Med. 1999;160:1862-68.

14. Lofdahl CG, Reiss TF, Leff JA, et al. Randomised, placebo controlled trial of effect of a leukotriene receptor antagonist, montelukast, on tapering inhaled corticosteroids in asthmatic patients. BMJ. 1999;319:87-90.

15. Tonelli M, Zingoni M, Bacci E, et al. Short-term effect of the addition of leukotriene receptor antagonists to the current therapy in severe asthmatics. Pulm Pharmacol Ther. 2003;16:237-40.

16. Fish JE, Israel E, Murray JJ, et al. Salmeterol powder provides significantly better benefit than montelukast in asthmatic patients receiving concomitant inhaled corticosteroid therapy. Chest. 2001;120:423-30.

17. Busse W, Nelson H, Wolfe J, et al. Comparison of inhaled salmeterol and oral zafirlukast in patients with asthma. J Allergy Clin Immunol. 1999;103:1075-80.

18. Ollendorf D, Pozniak A, Bowers B, Oster G. Economic impact of salmeterol versus leukotriene modifiers in patients with chronic asthma. Chest. 2000;118(4):185S.

19. Price DB, Ben-Joseph RH, Zhang Q. Changes in asthma drug therapy costs for patients receiving chronic montelukast therapy in the U.K. Respir Med. 2001;95:83-89.

20. Sheth K, Borker R, Emmett A, et al. Cost-effectiveness comparison of salmeterol/fluticasone propionate versus montelukast in the treatment of adults with persistent asthma. Pharmacoeconomics. 2002;20:909-18.

21. Menendez R, Stanford RH, Edwards L, et al. Cost-efficacy analysis of fluticasone propionate versus zafirlukast in patients with persistent asthma. Pharmacoeconomics. 2001;19:865-74.

22. Pathak DS, Davis EA, Stanford RH. Economic impact of asthma therapy with fluticasone propionate, montelukast, or zafirlukast in a managed care population. Pharmacotherapy. 2002;22:166-74.

23. Kelly HW. Comparison of inhaled corticosteroids. Ann Pharmacother. 1998;32:220-32.

24. Rosenbaum P, Rubin D. The central role of the propensity score in observational studies for causal effects. Biometrika. 1983;70:41-55.

25. Cochran WG. The effectiveness of adjustment by subclassification in removing bias in observational studies. Biometrics. 1968;24:295-313.
26. Rubin DB, Thomas N. Matching using estimated propensity scores: relating theory to practice. Biometrics. 1996;52:249-64.

27. Chen Y, Dales R, Tang M, Krewski D. Obesity may increase the incidence of asthma in women but not in men: longitudinal observations from the Canadian National Population Health Surveys. Am J Epidemiol. 2002;155:198-202.

28. Guerra S, Sherrill DL, Bobadilla A, et al. The relation of body mass index to asthma, chronic bronchitis, and emphysema. Chest. 2002;122:1256-63.

29. Shaheen SO, Sterne JA, Montgomery SM, Azima H. Birth weight, body mass index and asthma in young adults. Thorax. 1999;54:396-402.

30. Kuo A, Craig TJ. A retrospective study of risk factors for repeated admissions for asthma in a rural/suburban university hospital. J Am Osteopath Assoc. 2001;101:S14-S17; quiz S517-S518.

31. Hessel PA, Mitchell I, Tough S, et al. Risk factors for death from asthma. Prairie Provinces Asthma Study Group. Ann Allergy, Asthma Immunol. 1999; 83:362-68

32. Cockcroft DW, Swystun VA. Asthma control versus asthma severity. J Allergy Clin Immunol. 1996;98:1016-18.

33. Perkins SM, Tu W, Underhill MG, Zhou X, Murray MD. The use of propensity scores in pharmacoepidemiologic research. Pharmacoepi Drug Safety. 2000;9:93-101.

34. Drazen JM, Israel E. Should antileukotriene therapies be used instead of inhaled corticosteroids in asthma? Yes. Am J Respir Crit Care Med. 1998;158: 1697-98.

35. Stoloff SW, Stempel DA, Meyer J, et al. Improved refill persistence with fluticasone propionate and salmeterol in a single inhaler compared with other controller therapies. J Allergy Clin Immunol. 2004;113:245-51.

36. Reinus JF, Persky S, Burkiewicz JS, et al. Severe liver injury after treatment with the leukotriene receptor antagonist zafirlukast. Ann Intern Med. 2000; 133:964-68.

37. Wechsler ME, Pauwels R, Drazen JM. Leukotriene modifiers and ChurgStrauss syndrome: adverse effect or response to corticosteroid withdrawal? Drug Saf. 1999;21:241-51.

38. Sivri A, Coplu L. Effect of the long-term use of inhaled corticosteroids on bone mineral density in asthmatic women. Respirology. 2001;6:131-34.

39. Israel E, Banerjee TR, Fitzmaurice GM, et al. Effects of inhaled glucocorticoids on bone density in premenopausal women. N Engl J Med. 2001;345:941-47.

40. Tug T, Kamanli A, Tug E. Effects of long-term inhaled steroid use on bone mineral density in asthma patients. J Investig Allergol Clin Immunol. 2001;11:300-02.

41. Elmstahl S, Ekstrom H, Galvard H, Jet al. Is there an association between inhaled corticosteroids and bone density in postmenopausal women? J Allergy Clin Immunol. 2003;111:91-96.

42. Armstrong EP, Malone DC. Fluticasone is associated with lower asthmarelated costs than leukotriene modifiers in a real-world analysis. Pharmacotherapy. 2002;22:1117-23.

43. Orsini L, Limpa-Amara S, Crown WH, Stanford RH, Kamal K. Asthma hospitalization risk and costs for patients treated with fluticasone propionate vs montelukast. Ann Allergy Asthma Immunol. 2004;92:523-29.

44. Stempel DA, O'Donnell JC, Meyer JW. Inhaled corticosteroids plus salmeterol or montelukast: effects on resource utilization and costs. J Allergy Clin Immunol. 2002;109:433-39.

45. Stempel DA, Meyer JW, Stanford RH, Yancey SW. One-year claims analysis comparing inhaled fluticasone propionate with zafirlukast for the treatment of asthma. J Allergy Clin Immunol. 2001;107:94-98.

46. Stempel DA, Mauskopf J, McLaughlin T, et al. Comparison of asthma costs in patients starting fluticasone propionate compared to patients starting montelukast. Respir Med. 2001;95:227-34.

47. O'Connor RD, O'Donnell JC, Pinto LA, et al. Two-year retrospective economic evaluation of three dual-controller therapies used in the treatment of asthma. Chest. 2002;121:1028-35.

48. Snyder L, Blanc PD, Katz PP, et al. Leukotriene modifier use and asthma severity: how is a new medication being used by adults with asthma? Arch Intern Med. 2004;164:617-22. 
49. Schultz A, Stuck BA, Feuring M, et al. Novel approaches in the treatment of allergic rhinitis. Curr Opin Allergy Clin Immunol. 2003;3:21-27.

50. Phipatanakul W, Eggleston PA, Conover-Walker MK, et al. A randomized, double-blind, placebo-controlled trial of the effect of zafirlukast on upper and lower respiratory responses to cat challenge. J Allergy Clin Immunol. 2000;105: 704-10.

51. Corren J, Spector S, Fuller L, et al. Effects of zafirlukast upon clinical, physiologic, and inflammatory responses to natural cat allergen exposure. Ann Allergy Asthma Immunol. 2001;87:211-7.

52. Nathan RA. Pharmacotherapy for allergic rhinitis: a critical review of leukotriene receptor antagonists compared with other treatments. Ann Allergy Asthma Immunol. 2003;90:182-90; quiz 190-91, 232.

53. U.S. Food and Drug Administration. Center for Drug Evaluation and Research. Efficacy supplements approved in calendar year 2002. Available at: http://www.fda.gov/cder/rdmt/ESCY02AP.HTM. Accessed October 6, 2005.
54. Lakomski PG, Chitre M. Evaluation of the utilization patterns of leukotriene modifiers in a large managed care health plan. J Manag Care Pharm. 2004;10(2):115-21.

55. Shireman TI, Heaton PC, Gay WE, et al. Relationship between asthma drug therapy patterns and health care utilization. Ann Pharmacother. 2002;36 557-64.

56. Clark DO, Von Korff M, Saunders K, et al. A chronic disease score with empirically derived weights. Med Care. 1995;33:783-95.

57. Bright R, Avorn J, Everitt D. Medicaid data as a resource for epidemiologic studies: strengths and limitations. J Clin Epidemiol. 1989;42:937-45. 